\title{
Quantification of Voids and Delaminations in Real Concrete and Masonry Structures with Active Thermography: Case Studies
}

by Ch. Maierhofer*, R. Arndt*, M. Röllig*, R. Helmerich*, A. Walther**, B. Hillemeier** and C. Rieck ${ }^{* * *}$

${ }^{*}$ Federal Institute for Materials Research and Testing (BAM), Berlin, Germany **Department of Building Materials and Building Material Examination, Technical University of Berlin (TUB), Germany

***Institute for Material Testing (MPA), Berlin-Brandenburg, Germany

\begin{abstract}
Active thermography by inducing a non-stationary temperature distribution in combination with the analysis of temporal data in frequency domain (pulse phase thermography) is very well suited for the visualisation of inhomogeneities and defects close to the surface (up to a depth of $10 \mathrm{~cm}$ ) of building structures. But for quantitative analysis of data recorded on the building site, the main problems are manifold. In this paper, the results of several case studies will be presented involving the investigation of masonry and concrete structures.
\end{abstract}

\section{Introduction}

As shown in recent publications $[1,2,3]$, active thermography by inducing a non-stationary temperature distribution (e. g. impulse thermography) in combination with the analysis of temporal data in frequency domain (e.g. pulse phase thermography) is very well suited for the visualisation of inhomogeneities and defects close to the surface (up to a depth of $10 \mathrm{~cm}$ ) of building structures. For quantitative analysis of data recorded on-site, the main problems are manifold: the inaccessibility of most of the investigated structures, the changing environmental conditions, the inhomogeneity of the investigated surfaces and the relatively thick building structures in relation to the low thermal diffusivity of the building materials have to be considered. Although a lot of investigations of different measurement problems occurring in civil engineering have been carried out, most of the hitherto presented are results of laboratory measurements.

In this paper, the results of several case studies will be presented. These applications so far involve the investigation of the masonry structure behind plaster, the location of plaster delaminations, the location of voids below a stone pavement, the location of asphalt delaminations on concrete bridges and the location of delaminations of carbon fibre reinforced plastics (CFRP) for reinforcing concrete structures. Due to the high sensitivity of active thermography to defects at depths between 0.1 and $10 \mathrm{~cm}[2,4,5]$, it is complementary to other non-destructive testing methods like radar, ultrasonics and impact-echo successfully applied in civil engineering. These techniques achieve reliable results only starting from depth of 5 to $10 \mathrm{~cm}$ and deeper [6].

For performing on-site investigations, the measurement equipment has to be mobile, light, flexible, water resistant and easy to apply with a maximum of two operators. To overcome the obstacles given by the external conditions, different kinds of heating units including radiant and fan heaters, flash and halogen lamps in combination with a mobile computing unit for digital data recording in real time and a flexible infrared-camera for stationary and moved measurements were used. Data 
analysis was performed in time domain (maximum contrast of defects or inhomogeneities) and frequency domain (pulse phase thermography). Quantitative information about the lateral geometry of defects was gained from lateral temperature distribution. Even more difficult is the analysis of the defect depth, which might be performed semi empirically (e. g. by determining the blind frequency in the phase images [7]) or by a comparison of experimental data to the results of numerical simulations [8].

\section{Experimentals}

The experimental set-up for active thermography usually consists of a heating unit, an infrared camera (here: Inframetrics SC1000 with a focal plane area of $256 \times 256$ detectors being sensitive at wavelength from 3 to $5 \mu \mathrm{m}$ ) and a computer system enabling the recording of thermal images in real time. Here, a maximum image frequency of $50 \mathrm{~Hz}$ was achieved. Depending on the distance of the camera and the selected lenses, usually a surface area of about $1 \mathrm{~m}^{2}$ was investigated.

For obtaining a homogeneous heating of the surface to be investigated, three infrared radiators were aligned linearly having a power of $2400 \mathrm{~W}$ each. By using a rail system with a stepping engine, this heating unit could be moved automatically and steady going along the surface. The distance to the surface is variable, normally a distance of $15 \mathrm{~cm}$ was selected providing a homogeneous and efficient heating. Typical heating times between 5 and 60 min were selected.

Beside this system, the radiators can also be mounted horizontally on a trolley to perform on-site investigations on floors. If a low heating power is sufficient, e.g. for the detection of delamination of thin coatings, also fan heaters with a power of $2000 \mathrm{~W}$, halogen lamps and flash lights can be used. Together with an automatic scanner system, the previous ones are very well suited for the investigation of compound and adhesion of CFRP laminates, which are used for subsequent reinforcing of concrete and masonry structures [9].

In the following, different case studies performed directly at the building site and in the laboratory are presented demonstrating different heating sources and terms of data analysis and presentation.

\section{Data analysis}

Qualitative analysis of the recorded data can be performed already from the thermal contrast in the single thermograms. The image contrast of the defects can be enhanced by the application of pulse phase thermography (PPT), which is based on the analysis of each pixel of a series of thermal images describing the cooling down behaviour after heating in frequency domain by applying the Discrete Fourier Transformation [7]. One obtains amplitude and phase images for different frequencies. Especially in the phase images, the contrast of the defects is enhanced. In the following experiments, the heating pulse is represented as a square pulse, which can be described as superposition of different frequencies with varying amplitudes. The available energy is concentrated in the low frequencies. The pulse duration determines the frequency spectrum in a way, that for longer pulses lower frequencies contain more energy and therefore more information. This is exceedingly true for the long pulse durations necessary for the investigation of concrete of up to $1.5 \mathrm{~h} \mathrm{[1].} \mathrm{The} \mathrm{maximum} \mathrm{frequency} \mathrm{is} \mathrm{determined} \mathrm{by} \mathrm{the} \mathrm{acquisition} \mathrm{rate,} \mathrm{the} \mathrm{minimum}$ frequency is limited by the recording time and can be decreased by increasing the data set subsequently, e. g. by zero padding. In practice only the first images at low frequencies are of interest, since most of the energy is concentrated here. Higher frequencies exhibit a higher noise level. 
Quantitative results are obtained by analysing the transient curves (temperature as a function of time for each pixel). The difference curve of transients above a defect and above the sound area usually has a distinct maximum $\Delta T_{\max }$ at a time $t_{m a x}$. In the respective thermogram, the defect can be observed with maximum temperature contrast. These two values are influenced by the thermal properties of the defect and the embedded material, the geometry (size and depth) of the defect and of the duration and energy for heating. The Inverse Problem can be solved by comparing the experimental data with numerical simulations $[8,10]$.

The quantitative approximation of PPT is based on the blind frequency $f_{b}$, which is the frequency at which the detectability of an inhomogeneity drops to zero (coming from lower frequencies) [7]. Thus, the blind frequency decreases as the depth of the voids increases. But due to the high noise level at higher frequencies, often the inaccuracy of the blind frequency is very high and other approaches are required as described in $[11,12]$.

\section{Case studies}

In the frame of the European research project ONSITEFORMASONRY [13], several case studies were performed at selected historic sites by applying different strategies for the application and combination of non-destructive, minor-destructive and partly destructive testing methods. Two of these investigations obtained at the Wartburg in Eisenach, Germany, and at the Altes Museum in Berlin are demonstrated below.

On-site investigations at a concrete bridge for the detection of asphalt delamination and on a floor covered with granite tiles were part of a national project concerning the development of active thermography for application in civil engineering, funded by the DFG (Deutsche Forschungsgemeinschaft).

A new automated scanner system for on-site testing of CFRP laminates on concrete bridges with active thermography was developed in the EC project Sustainable Bridges.

\subsection{Location of a walled-up door behind plaster in the Wartburg Castle, \\ Eisenach}

The Wartburg Castle (see fig. 1 left) represents a long history going back to the $12^{\text {th }}$ century and belongs to the World Cultural Heritage. The Palas is the first of its kind in Germany and is well documented. Based on the results of intensive building research of the Wartburgstiftung (Foundation of Wartburg), detailed problems could be compiled in close contact with the responsible researches, architects and restorers.

In the Landgrafenzimmer, a room at the north site in the $1^{\text {st }}$ floor of the Palas, the internal structure of the north wall to the staircase had to be investigated. It was assumed that there had been a door, which was walled up. The outer surface of the wall in the Landgrafenzimmer consists of plaster with ornaments and paintings. The other surface of the wall at the staircase, which was built in 1950, is covered with white painted plaster.

The aim of the investigations with impulse-thermography was to localise this former door opening. The investigated area was about $3.5 \mathrm{~m}$ in horizontal and $1.2 \mathrm{~m}$ in vertical length and was located above a showcase. Each square meter of this area was heated up with a fan heater for about $5 \mathrm{~min}$. Afterwards, thermograms were recorded with a frequency of $2 \mathrm{~Hz}$ for about $15 \mathrm{~min}$ using the above described infrared camera. After data recording, PPT was applied for data analysis. A phase image at a frequency of $\mathrm{f}=2.46 \times 10^{-4} \mathrm{~Hz}$ from a section with a width of about $1 \mathrm{~m}$ is displayed in fig. 1 right. It clearly shows the masonry and mortar structure in the 
lower part of the wall with an arc-shaped boundary on its upper part, which corresponds to the shape of the walled-up door. In the upper part of the wall no masonry-structures are visible. More information about the investigations at Wartburg is published in [14].
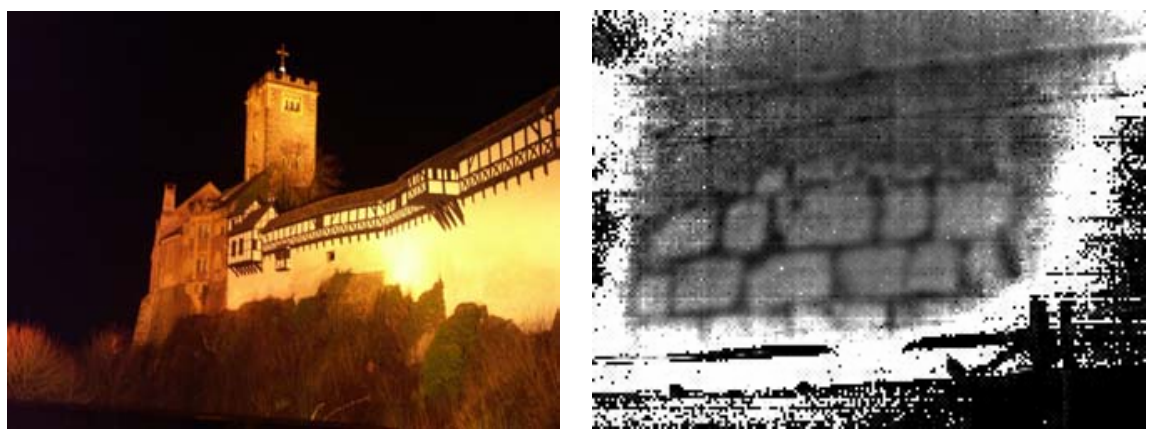

Fig. 1. Left: View of Wartburg in Eisenach, Germany. Right: Phase image at $f=2.46 \times 10^{-4} \mathrm{~Hz}$ recorded with pulse phase thermography showing the walled door behind the plaster at the Landgrafenzimmer of the Wartburg.

\subsection{Detection of plaster delaminations at a sandstone column inside the rotunda of the Altes Museum in Berlin}

The Altes Museum (old museum) in the city centre of Berlin was designed by Karl Friedrich Schinkel and was built between 1823 und 1830 on the Lustgarten. Fig. 2 shows a view from the Lustgarten. The building was designed with an atrium containing pillars and a central cupola related to the Roman Pantheon and having antique temples as an archetype. It represents the eldest exhibition hall in Berlin. During the Second World War parts of the Altes Museum burned down, and it was rebuilt in 1966.

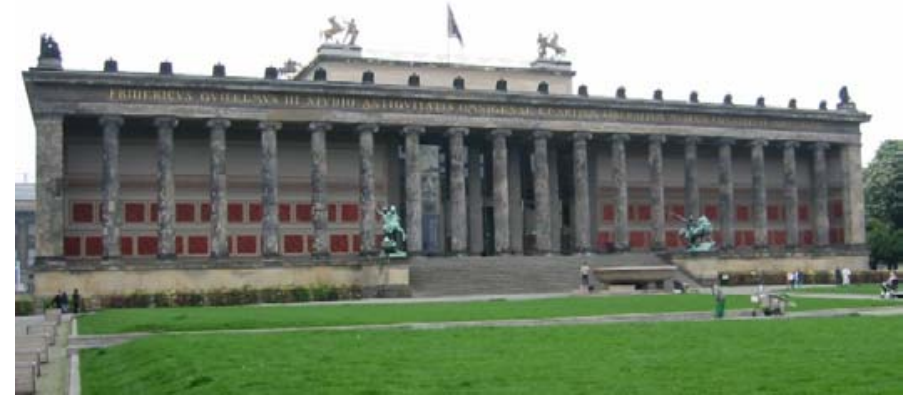

Fig. 2. Altes Museum in Berlin-Mitte, view from the Lustgarten.

In 1999, the planning stage started for a broad reconstruction in the frame of a master plan concerning the whole Museumsinsel (Museum Island) taking into account contemporary requirements for a museum building. Extensive investigations have to be performed to assure structural integrity and to provide a basis for a sustainable and considerable conversion of the building, which should be completed until 2009.

The columns in the rotunda belong to the original asset from 1830 (see fig. 3 left). The columns consist of massive sand stone, which is covered with lime plaster 
having a thickness of 2 to $3 \mathrm{~cm}$. This plaster is the carrying layer for the visible stucco marble layer of 3 to $6 \mathrm{~mm}$. The sand stone core is massive and it was revealed with radar that it consists of single drums [15]. The whole surface of the columns is covered with a net of small cracks. The cracks are very thin, but few of these have a width of up to $2 \mathrm{~mm}$. By knocking on the surface, different types of delaminations can be assumed: Delaminations of the stucco marble layer, delaminations of the plaster and a combination of both. One column had been selected for investigations with impulse thermography to locate and quantify these delaminations. Again, for the heating of the surface of the columns a conventional electric fan heater has been used with a heating power of $2000 \mathrm{~W}$ avoiding temperatures at the surface higher than $50{ }^{\circ} \mathrm{C}$. Each section of the column with a height of $1 \mathrm{~m}$ was heated for about 5 min. For accessing all parts of the column, a lift was used. Large areas with delamination appear in the images of the lower parts of the column as demonstrated in the warmer part of the thermogram in fig. 3 middle and in the dark parts of the phase image at $5.56 \times 10^{-4} \mathrm{~Hz}$ in fig. 3 right. From comparisons with results obtained at test specimens with different mortar thickness in the laboratory [16], it is assumed that these delaminations belong to the stone/mortar interface.

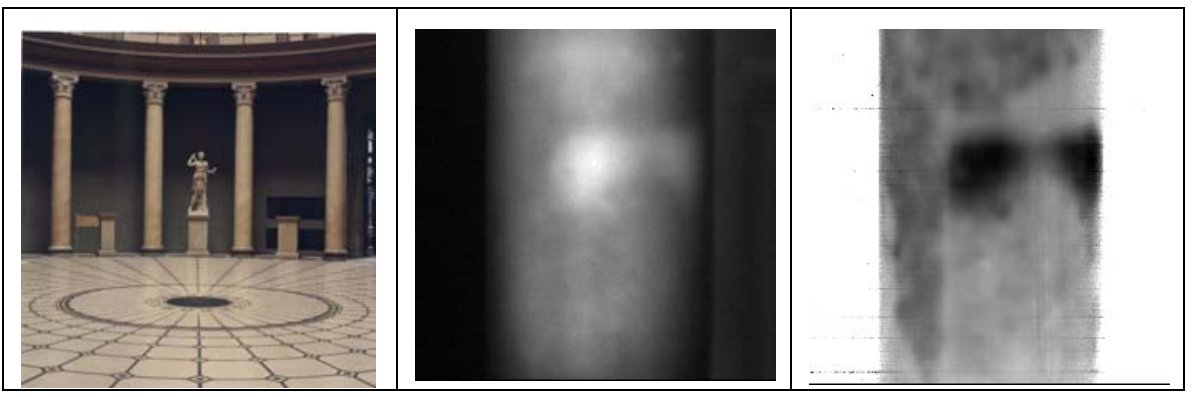

Fig. 3. Left: Rotunda of the Altes Museum with plastered sandstone columns Middle: Thermogram at a selected area after 5 min heating. The temperature range was scaled from 20 to $30^{\circ} \mathrm{C}$. The delamination appears as white area (high temperature). Right: Phase image of the same area at $5.56 \times 10^{-4} \mathrm{~Hz}$. The delamination appears as dark area.

\subsection{Location of voids below a stone pavement}

For the detection of voids below a stone pavement consisting of granite tiles with a thickness of $1.5 \mathrm{~cm}$, which were laid on mortar on a concrete floor, a whole area of $40 \mathrm{~m}^{2}$ was investigated. Single areas of about $1 \mathrm{~m}^{2}$ were heated up with an infrared radiator for about $3 \mathrm{~min}$. The cooling down behaviour was recorded with the infrared camera. The voids could be easily detected with a temperature difference of about $2.5 \mathrm{~K}$ as shown in fig. 4. Here, the superpositioning of the photogrammetric equalised digital photo as well as of the equalised thermogram recorded $1.33 \mathrm{~min}$ after switching off the heating source is displayed. From the photo, the position of the joints can be clearly derived which shows that the main voids appear at the edges and sometimes also along the joints of the tiles. 

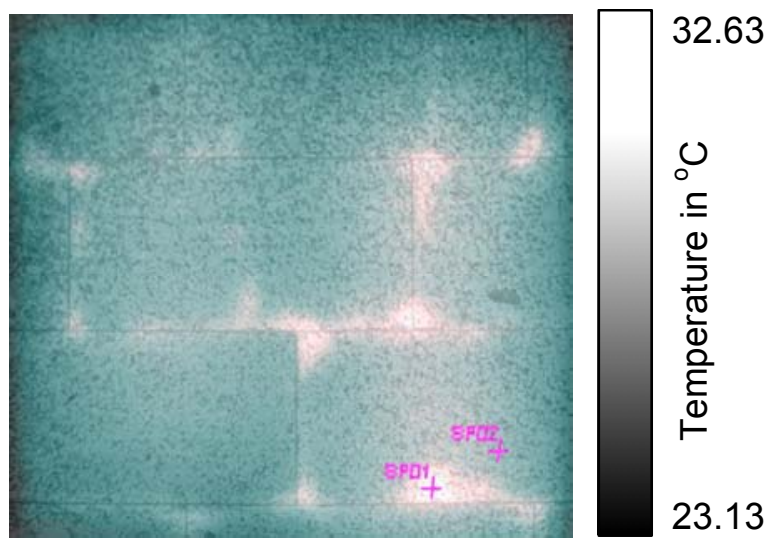

Fig. 4. Superpositioning of an equalised digital photo and the related equalised thermogram of several granite tiles $\left(1 \times 1 \mathrm{~m}^{2}\right)$ recorded after a heating time of $3 \mathrm{~min}$. The voids could be clearly detected as warmer (white) areas.

\subsection{Location of asphalt delamination on a concrete bridge}

For the location of voids and delamination under asphalt, also the sun can be used as heating source to generate a non-stationary heat transfer. For assessing the expected temperature difference of a delamination and the optimum time for data recording, numerical simulations were performed by Finite Element Modelling with ANSYS. At the beginning of the simulation, the temperature of the structure was set to $10{ }^{\circ} \mathrm{C}$. The applied heat radiation was varied by linear increase from 0 to $300 \mathrm{~W} / \mathrm{m}^{2}$ for about $3 \mathrm{~h}$, afterwards the radiation was kept constant at $300 \mathrm{~W} / \mathrm{m}^{2}$ again for a duration of $3 \mathrm{~h}$. As a structure, a concrete plate with a thickness of $30 \mathrm{~cm}$ covered by an asphalt layer with a thickness of $7 \mathrm{~cm}$ was assumed. Between both layers, a $1 \mathrm{~mm}$ bitumen sheet was positioned. As a defect, a $20 \times 20 \mathrm{~cm}^{2}$ delamination of the bitumen sheet was assumed. As a result, the difference curve of the temperature above the delamination and above the sound area is displayed as a function of time in fig. 5. A maximum temperature difference of about $2.5 \mathrm{~K}$ is obtained after a heating time of about $5.7 \mathrm{~h}$. Therefore, the sun seems to be suitable as heating source for the detection of defects in and below asphalt layers by measuring the temperature distribution at the surface with an infrared camera.

On-site-investigations on a pre-stressed concrete bridge were carried out for the detection of voids or delamination inside or below the top asphalt layer. The paving above the concrete plate consisted of up to $50 \mathrm{~mm}$ concrete for levelling, $10 \mathrm{~mm}$ mastic for sealing and an asphalt layer with a thickness of $50 \mathrm{~mm}$. Thermal images were taken at varying times after sunrise, thus using the sun as a heating source. For performing the measurements, a small scaffold was installed (see fig. 6 left) enabling the positioning of the camera and having the possibility of shadowing of the area under investigation for avoiding the incidence of direct and reflected sunlight.

Fig. 6 right shows a thermogram taken at 10:00 a.m. at a measured solar radiation of $800 \mathrm{~W} / \mathrm{m}^{2}$. Clearly distinguishable are areas of higher temperature, which might be related to defects or delamination. The largest of these areas in the middle of fig. 6 right has a temperature difference of $3.5 \mathrm{~K}$ to it's surrounding. 


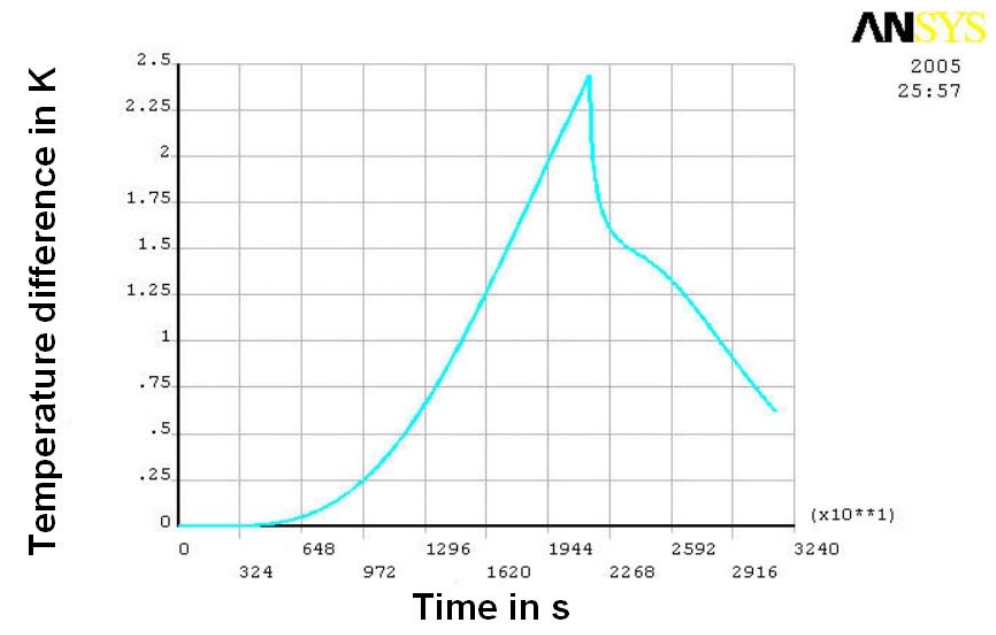

Fig. 5. Simulated temperature difference as a function of time for an asphalt layer with delamination and the sound area.
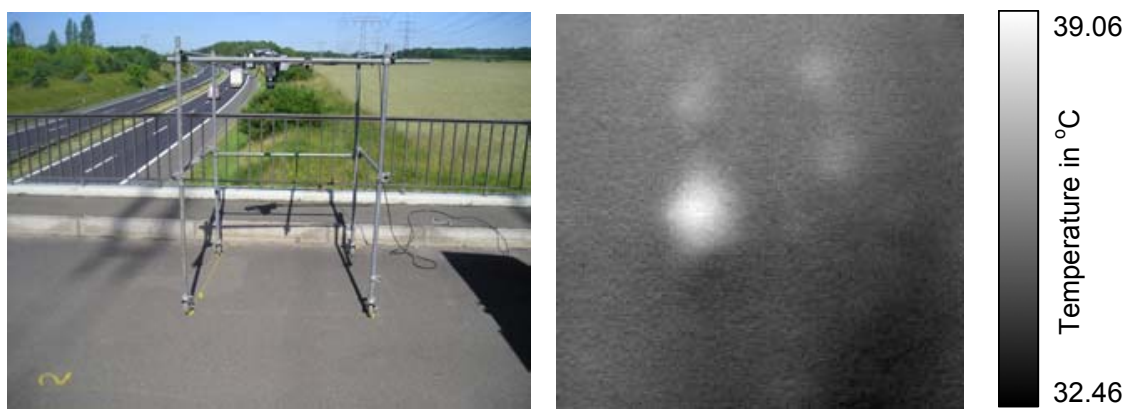

Fig. 6. Left: Small scaffold at the bridge with the mounted IR camera. Right:

Thermogram recorded at 10 a.m. summer time, 2005-06-23, sun, in Berlin of a $1 \times 1 \mathrm{~m}^{2}$ sized area of an asphalt layer on a concrete bridge. The delaminations are clearly shown as warmer areas.

\subsection{CFRP laminates}

Deterioration of concrete bridges leads to cracks, corrosion of the reinforcement or spalling of the concrete cover. For repair and strengthening, remedial measures using CFRP-plates, rods or mineral covered grids are applied to the concrete surface. Insufficient application, aging effects due to heavy loads and environmental influences and further impacts may lead to damages of the applied CFRP-strengthening system like delamination and deterioration of the laminate structure, which can be easily detected with active thermography.

For on-site applications enabling automatic testing along large ranges, thus a new scanner system was developed consisting of flash lights as heating sources (1500 W each) as shown in fig. 7. For optimising and testing of this system, a reinforced concrete beam with a size of $0.3 \times 0.5 \times 5.2 \mathrm{~m}^{3}$ was constructed. In close cooperation with the laboratory for Structural Engineering at the Potsdam University of Applied Sciences, the beam was preloaded in a four point bending test with a 
maximum applied load of $100 \mathrm{kN}$, where flexural cracks of about $2 \mathrm{~mm}$ developed. The load was applied from underneath the beam, thus the thermography test set-up was chosen top-down for avoiding spalled concrete parts damaging the thermocamera and the heating unit.

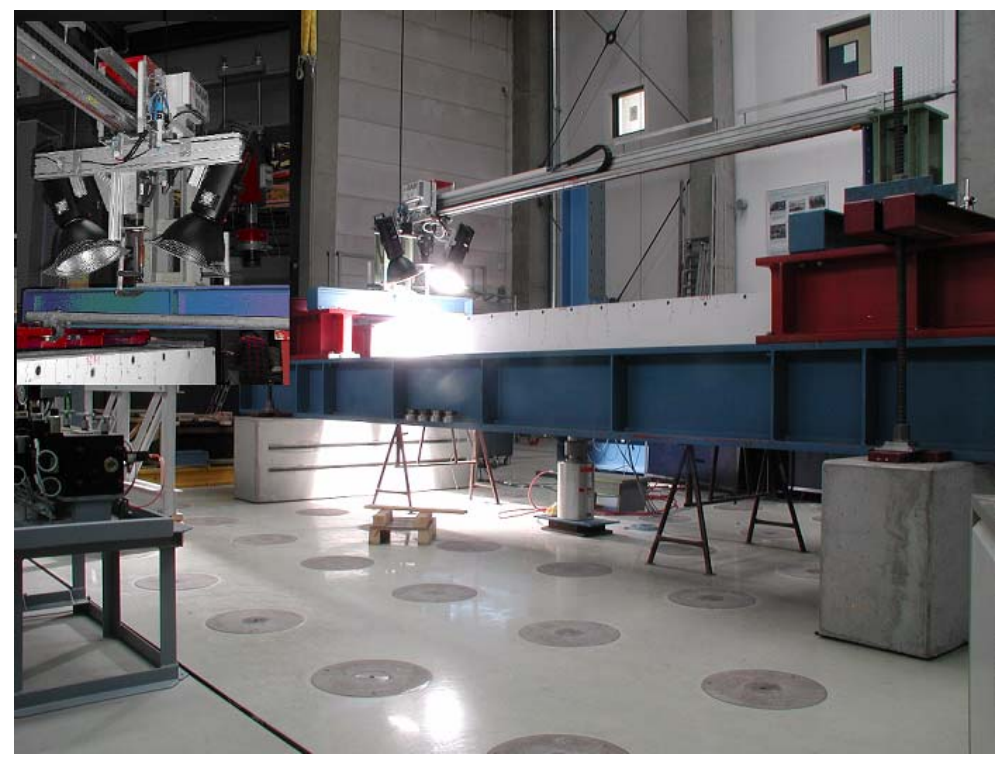

Fig. 7. Strengthened concrete beam during four point bending test with the thermographic scanner system showing the flash lights and the scanner axis.

Afterwards, the unloaded beam was repaired with two $100 \mathrm{~mm}$ STO BPE 1410 CFRP-plates, which were mounted to the tension zone on the top of the beam. The strengthened beam was loaded in several cycles with increased load in the four point bending test. For detecting early debonding, active thermography was applied after each cycle by using the thermal scanner system. Consecutively, an area with a length of about $30 \mathrm{~cm}$ was heated up with flashlight by applying a serial of 7 flashes. The cooling down behaviour was observed for $5 \mathrm{~min}$. The data were analysed by applying PPT.

The $1 / 3$ points of the beam length turned out to be the weakest cross sections in shear. The failure emerged immediately, after new shear cracks propagated at about $5 \%$ below ultimate load $(295 \mathrm{kN})$. The CFRP-plate debonded at the superposition of flexural and shear cracks. In fig. 8, three phase images recorded at $3.33 \times 10^{-3} \mathrm{~Hz}$ are shown after a load of 180,285 and $295 \mathrm{kN}$, respectively. After a load of $180 \mathrm{kN}$, a homogeneous phase distribution is shown giving no hints to unintentionally included delaminations. First inhomogeneities in the phase images can be observed after a load of $275 \mathrm{kN}$, which became more clear after a load of $285 \mathrm{kN}$ displayed in fig. 8 middle. After a load of $295 \mathrm{kN}$, in $1 / 3$ of the beam length the rod was completely delaminated along the cross section. In the related phase image in fig. 8 right, complete delamination can be detected. 


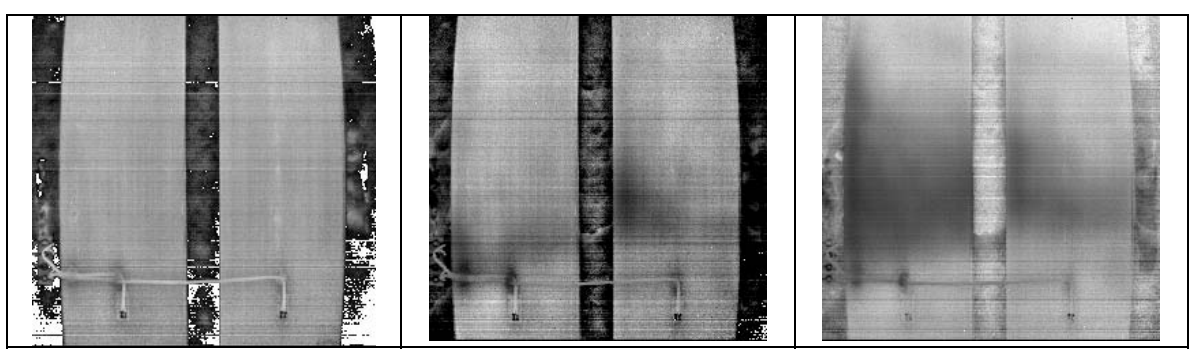

Fig. 8. Phase images at a frequency of $3.33 \times 10^{-3} \mathrm{~Hz}$ recorded after a load of $180 \mathrm{kN}$ (left), $285 \mathrm{kN}$ (middle) and $295 \mathrm{kN}$ (right).

\section{Summary and Conclusion}

In the above mentioned case studies, impulse thermography was applied to a multitude of different testing problems related to the detection of defects and delamination very close to the surface, i. e. up to a depth (cover) of about $7 \mathrm{~cm}$. In most of these case studies, data analysis based on PPT enhances the contrast of the defects to be detected and reduces the influence of inhomogeneous heating, which often occurs if the surface is heated manually, and of inhomogeneities on the surface. Quantitative analysis is mainly related to the lateral size of the defects, although in some cases also data is needed for quantifying the depth. For depth analysis, the comparison of experimental data to numerical simulations can be performed. Here, it has to be considered that at the beginning of the investigations, the building structure is not in thermal equilibrium with the ambiance, e.g. due to heating of the interior during the investigation of an exterior wall or due to the influence of the sun light.

The presented results clearly show that the applied methodology is very well suited for applications in civil engineering. The only requirements for on-site applicability are a power supply and the accessibility of the surface under investigation. In some cases, a maximum surface temperature should not be exceeded for not damaging the surface or the adhesive. Horizontal as well as vertical structures can be investigated. Therefore, the method can be applied for assessment of the current condition as well as for quality assurance after maintenance and construction measures. Further developments are related to systems, which are adapted to automatic investigation of distinct testing problems along large areas.

\section{Acknowledgements}

Parts of the work were funded by the European Commission in the projects ONSITEFORMASONRY (www.onsiteformasonry.bam.de, EVK4-CT-2001-00060) and Sustainable Bridges (TIP3-CT-2003-001653). Basic research was performed in the frame of a national project (Struktur- und Feuchteuntersuchungen von Bauteilund Bauwerksoberflächen mit der Impuls-Thermografie) funded by the DFG (Deutsche Forschungsgemeinschaft). We acknowledge the help of Dr. Matthias Hemmleb for performing the rescaling and superpositioning of photo and thermogram in fig. 4.

\section{REFERENCES}

[1] Weritz, F., Arndt, R., Röllig, M., Maierhofer, Ch. and H. Wiggenhauser. Investigation of concrete structures with pulse phase thermography, Materials and Structures, 38 (2005) 731-737. 
[2] Vavilov, V., Kauppinen, T., and E. Grinzato. Thermal characterisation of defects in building envelopes using long square pulse and slow thermal wave techniques, Research Non-Destructive Evaluation, 9 (1997) 181-200.

[3] Carlomagno, G. M., Di Maio, R., Meola, C. and N. Roberti. Infrared thermography and geophysical techniques in cultural heritage conservation, Quantitative Infrared Thermography Journal, 2(1) (2005) 5-24.

[4] Wyss, P., Lüthi, T., Primas, R. and O. Zogmal. Factors affecting the detectability of voids by infrared thermography, in: Proceedings of QIRT 1996, Stuttgart, 1996, Edizioni ETS, Pisa (1997), pp. 227-232.

[5] Maierhofer, Ch., Brink, A., Röllig, M. and H. Wiggenhauser. Transient thermography for structural investigation of concrete and composites in the surface near region, Infrared Physics \& Technology, 43 (2002) 271-278.

[6] Maierhofer, Ch., Krause, M., Niederleithinger, E. and H. Wiggenhauser. Nondestructive testing methods at BAM for damage assessment and quality assurance in civil engineering, in: Proc. of the Int. Symp. of Non-Destructive Testing in Civil Engineering in Berlin, 2003, CDROM and www.dgzfp.de

[7] Ibarra-Castanedo, C. And X. P. V. Maldague. Pulsed phase thermography review, Quantitative Infrared Thermography Journal,1(1) (2005) 47-70.

[8] X.P.V. Maldague. Theory and Practice of Infrared Technology for NonDestructive Testing, John Wiley and Sons, New York (2001).

[9] Helmerich, R., Maierhofer, Ch., Röllig, M., Arndt, R. and J. Vielhaber. Bond quality survey of loaded RC-beams with CFRP-plate repair using impulsethermography, in: Proceedings of the Third International Conference on Bridge Maintenance, Safety and Management 16.-19. Juli 2006, Porto, Portugal, in print.

[10] Maierhofer, Ch., Wiggenhauser, H., Brink, A. and M. Röllig. Quantitative numerical analysis of transient IR experiments on buildings, Infrared Physics and Technology, 46 (2004) 173-180.

[11] C. Ibarra-Castanedo. Quantitative subsurface defect evaluation by pulsed phase thermography: depth retrieval with the phase, Phd-Thesis, Université Laval, Canada, 2005.

source: http://www.theses.ulaval.ca/2005/23016/23016.html.

[12] Arndt, R., Maierhofer, Ch. And M. Röllig. Quantitative Pulse-PhaseThermography for Masonry and Concrete Structures, in: Proceedings of the $9^{\text {th }}$ European Conference on NDT, Berlin, September 25-29, 2006, in print.

[13] On-site investigation techniques for the structural evaluation of historic masonry buildings, www.onsiteformasonry.bam.de, European Research Contract No. EVK4-CT-2001-00060.

[14] Ch. Hennen. Untersuchungen an der Wartburg, in: Tagungsband zum Feuchtetag 2004 mit Workshop ONSITEFORMASONRY, BAM Berlin, 18. und 19. November 2004, Berlin: DGZfP (2004) CD-ROM, presentation O3.

[15] Maierhofer, Ch., Hamann, M., Hennen, C., Knupfer, B., Marchisio, M., da Porto, F., Binda, L. and L. Zanzi. Structural evaluation of historic walls and columns in the Altes Museum in Berlin using non-destructive testing methods, in: Proc. Structural Analysis of Historical Constructions / 4th International Seminar on Structural Analysis of Historical Constructions, November 10-13, 2004, Padova, Italy (Proceedings) (2004), 331-341; Taylor \& Francis Group, London; Hrsg.: Lourenco \& Roca, Modena.

[16] Arndt, R., Maierhofer, Ch., Röllig, M., Weritz, F. und H. Wiggenhauser. Ortung von Putzablösungen auf Beton und Mauerwerk mit der Puls-PhasenThermografie, in: Tagungsband: DACH-Jahrestagung, 17.-19. Mai 2004, Salzburg, A, Berlin: DGZfP BB-CD 89, 2004, presentation 89. 